\title{
O CENÁRIO INTERNACIONAL, A NOVA EMPRESA E A NOVA COMPETIÇÃO
}

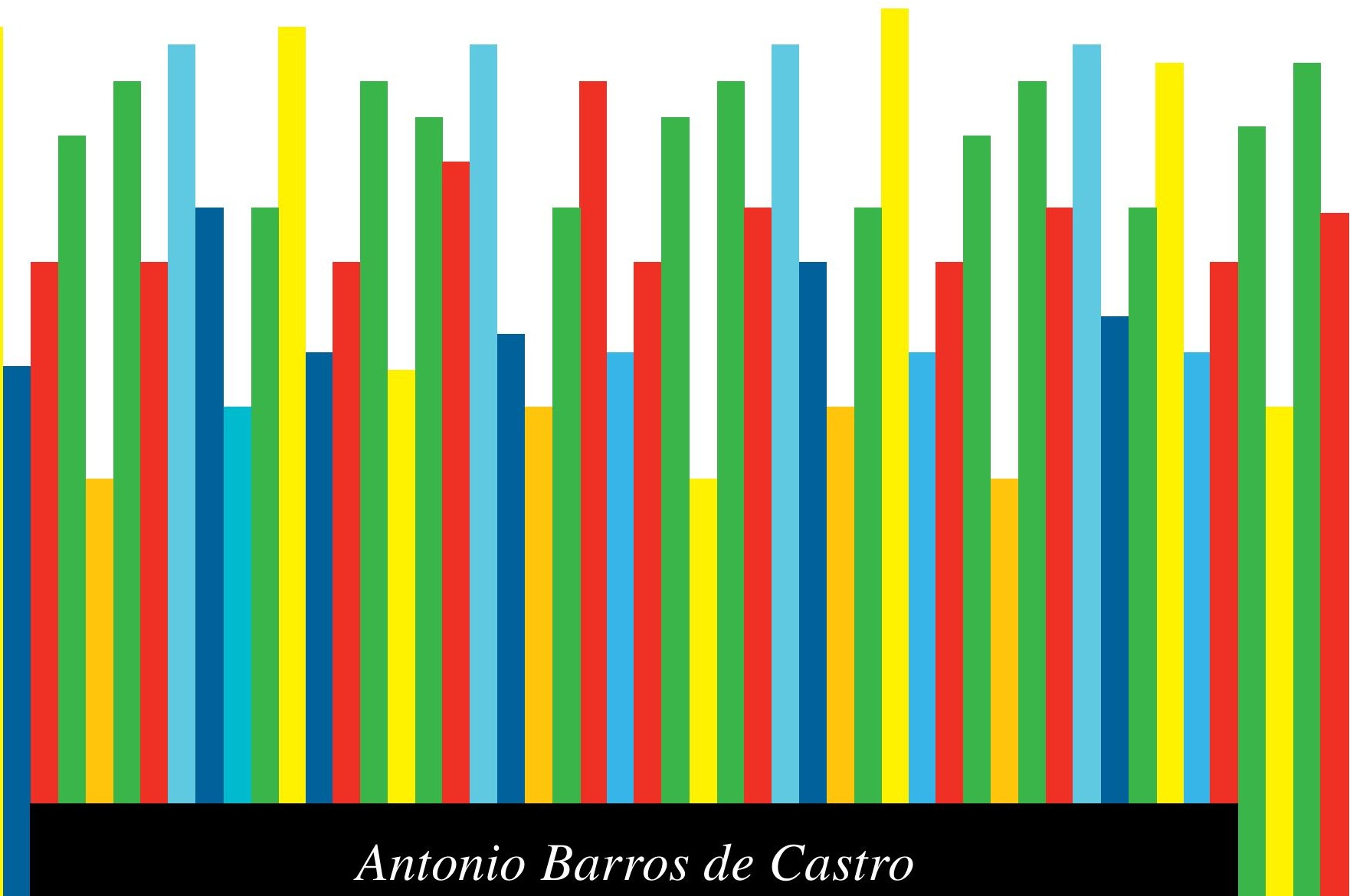


RESUMO

Este texto é a reprodução de um dos últimos artigos escritos pelo professor Antonio Barros de Castro. Com a experiência e a competência de uma vida dedicada à pesquisa sobre o setor produtivo brasileiro, Castro descreve de forma única as transformações econômicas no mundo e as mudanças nas estratégias de competição das firmas. Como tudo que é inovador, suas ideias sempre foram direcionadas para entender o futuro e a dinâmica do novo. O artigo descreve a revolução das tecnologias da informação e apresenta as características da nova empresa e dos novos padrões de competição. Na última parte do artigo, Castro argumenta que diversos fatores, mas, de forma especialmente relevante, os ativos intangíveis, o financiamento via mercado de capitais e as tecnologias da informação, dão margem para o surgimento de uma nova economia.

Palavras-chave: nova empresa, nova economia, competição, globalização.

\section{ABSTRACT}

This text is a reproduction of one of the last articles written by professor Antonio Barros de Castro. Drawing on the wealth of experience and expertise of his life - devoted to researching on the Brazilian production sector - Castro depicts in a unique way the economic transformations around the world and the changes in competition strategies among companies. As with everything innovative, he has always developed ideas geared towards understanding the future and the dynamics of what is new. The article describes the revolution brought about by information technologies, and presents the characteristics of the new company and the new competition patterns. In the last part of the article Castro advocates that several factors have triggered the onset of a new economy, and among them the leading factors are the intangible assets, capital market financing and the information technologies.

Keywords: new company, new economy, competition, globalization. 
A NOVA REVOLUÇÃO INDUSTRIAL. AS TECNOLOGIAS DA INFORMAÇÃO

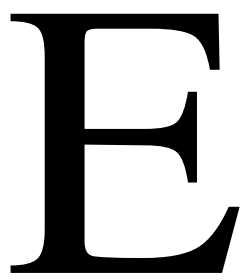

normes avanços tecnológicos foram obtidos nos últimos decênios em diversos terrenos. Pela sua influência sobre a maneira de se produzir, sobre o relacionamento dos agentes econômicos, e até mesmo sobre o cotidiano dos homens, nada se compara, contudo, aos avanços alcançados na capacidade de transmitir, processar e armazenar informações. De fato, o que mais distingue o quadro econômico atual do vigente até, digamos, 1980 é a transformação ocorrida nesses tipos de atividade, e suas imensas consequências. Daí a referência usual ao ingresso numa terceira revolução industrial e ao surgimento de uma "economia da informação" (ou "digital").

Assim como no caso dos têxteis nos últimos decênios do século XVIII e do aço na segunda metade do século XIX, os avanços recentemente alcançados no tocante a informações foram acompanhados de enorme barateamento e difusão do uso daquilo que poderia ser referido como o objeto central da revolução - respectivamente, o tecido industrializado, o aço, e as informações. É fácil perceber (Freeman \& Perez, 1988), além disso, que a última é também a mais transversal e ubíqua das revoluções industriais: sob a sua influência as fábricas, os hospitais e os próprios lares vêm sendo convertidos em ambientes crescentemente semelhantes. Assinalo, no que segue, algumas propriedades de uma economia crescentemente densa em informações.

$$
* * *
$$

A maior capacidade de colher informações, de processá-las, e de simular situações tende a traduzir-se em maior capacidade de formular hipóteses, de explorar possibilidades, de corrigir posições e, enfim, de resolver problemas. Consequentemente tende a haver mais criação, bem como mais cópia de produtos e processos - o que, se por um lado possibilita, por outro impõe a agilização das decisões.

Na mesma linha de raciocínio convém acrescentar que a base material da produção e os próprios produtos tendem a apresentar mais alternativas, opções e versatilidade. Aumenta também, exponencialmente, a importância das instruções ou programas (softwares) instalados nos equipamentos (hardwares). Isso amplia as possibilidades de automação - que se torna, por sua vez, muito mais flexível - enquanto os produtos e processos têm ampliadas as suas possibilidades de iteração. No limite, tende-se a gerar equipamentos, insumos e produtos finais "inteligentes".

Como decorrência do anterior, multiplicam-se as possibilidades de adaptação dos produtos às preferências dos demandantes ("customização" da produção). Intensifica-se, com isso, o relacionamento das empresas com seus fornecedores e clientes. Se tudo isso agiliza e potencia a competição, cabe frisar que também multiplica as oportunidades de cooperação ${ }^{1}$.

$\mathrm{O}$ que precede sugere o surgimento de uma economia que poderíamos denominar de "decisão intensiva". Nela encontram-se valorizados o gerenciamento, as escolhas por parte dos consumidores, e a participação dos trabalhadores na produção. Estes últimos, aliás, passam por vezes a ser referidos como “colaboradores", denominação que não teria cabimento, seja na velha fábrica trabalho-intensiva, seja no mundo da automação rígida.

Mas trata-se também de uma economia de relações intensivas, dada a maior interação das empresas entre si, com os consumidores e, em certos ramos, com as universidades e os centros de pesquisa. Especialmente no tocante aos setores tecnologicamente mais avançados, o inter-relacionamento chega a ser de tal ordem que praticamente desaparece o conceito tradicional de empresa, surgindo em seu lugar a realidade das redes (Castels, 1996).

Por outro lado, dadas a mutabilidade ambiental, a maior contestabilidade das posições e a multiplicação dos caminhos alternativos, é altamente valorizada a formulação de estratégias.

\section{ANTONIO BARROS} DE CASTRO

(1938-2011)

foi professor emérito

do Instituto

de Economia

da Universidade

Federal do Rio de

Janeiro e presidente

do Banco Nacional

de Desenvolvimento

Econômico

e Social (BNDES).

Antonio Barros deCastro deixou um grande legado de textos publicados e não publicados. O tex to que aqui se apresenta constitui a primeira partedorelatório de pesquisa entregue ao Banco de Desenvolvimento do Estado de Minas Gerais, escrito em 2003 e posteriormente revisto, denominado "A Economia Mineira no Século XXI Diagnósticoe Perspectivas". O título original do trabalho era "O Quadro Internacional e a Evolução Recente da Economia Brasileira" (nota de Ana Célia Castro).

1 No tocante à competição, ver Best (1990). 
Estamos, em suma, e como se tratou de sublinhar, diante de um novo tipo de economia - aqui poderíamos a ela nos referir como "decisão intensiva e relação intensiva".

Indiscutivelmente entra agora mais conhecimento na produção do que no passado. A produção corrente continua, no entanto, fundamentalmente guiada por rotinas, e o conhecimento usado pelas empresas encontra-se em grande medida embutido em equipamentos e insumos. É bem verdade que a linguagem digital potencia a capacidade de pesquisa e prototipagem de produtos e processos. Mas a prevalência, como no passado, das rotinas e do conhecimento tácito, parece não recomendar o emprego da denominação "economia do conhecimento". O conhecimento, enquanto tal, continua a ser a matéria-prima bem como o produto das universidades - e é o bom relacionamento das universidades com as empresas que permite a certos países ingressar e se manter em posição de liderança.

\section{GLOBALIZAÇÃO COMO INTENSIFICAÇÃO DAS TROCAS E DOS FLUXOS FINANCEIROS INTERNACIONAIS}

O projeto de reconstrução de um sistema mundial de comércio altamente integrado, onde os fluxos financeiros pudessem livremente deslocar-se, defendido pela delegação norte-americana em Bretton Woods e resistido, à época, pela Europa (e, a seguir, ainda mais acentuadamente, pelo Japão), foi plenamente retomado nos anos 1980. O fim da rodada Uruguai (1993) e a criação da Organização Mundial do Comércio praticamente oficializam a instauração de uma ordem internacional muito mais aberta e integrada.

A combinação da abertura com o avanço prodigioso das comunicações criava condições altamente favoráveis, não apenas ao comércio, como ao deslocamento (transplante) de unidades produtivas (plantas) das empresas sediadas nos grandes centros para nações que passavam a ser referidas como emergentes. Isso significava que a geração de valor na obtenção de diversos produtos passava a ser levada a efeito em diversos países, permanecendo, no entanto, as funções superiores - do tipo planejamento, pesquisa e desenvolvimento, e outras - sediadas nos países centrais (de preferência no país sede da empresa).

Poucos países da periferia foram efetivamente integrados no novo sistema - todos, porém, viram-se instados a ajustar-se aos requisitos da integração internacional através de reformas que visavam aproximar as instituições e práticas locais das vigentes nos países de origem das grandes empresas. Esse processo, como bem se sabe, foi inegavelmente liderado por instituições financeiras internacionais (onde o governo dos Estados Unidos tem peso decisivo), por empresas norte-americanas e pelo próprio governo desse país.

Com o processo de integração, usualmente referido como globalização, em pleno curso, o comércio internacional passou a crescer, já nos anos 1980, mais de 1,5 vez mais rápido que a produção mundial. $\mathrm{Na}$ década seguinte, o crescimento do comércio verificou-se em média o dobro $(8 \%$ ao ano) da velocidade de avanço da produção mundial. Já os fluxos de capital cresciam a um múltiplo da cifra para as transações comerciais.

Duas consequências do que acaba de ser dito serão aqui sublinhadas.

Primeiramente, o enorme alargamento dos mercados desencadeia uma verdadeira guerra por escalas mais amplas. Como consequência disso, e para numerosos artigos, a produção mundial passa a ser dominada (mais da metade do todo, digamos), mundialmente, por umas poucas empresas. Isso supõe aquisição de líderes locais por empresas mundiais e, claro, o desaparecimento de numerosas empresas. Tal tendência é sobretudo marcante nos ramos de alta tecnologia (Chandler, 2001).

Cabe também destacar que na corrida pela mundialização assim desatada as empresas norte-americanas levam grande van- 
tagem. E isso não apenas pela sua recente reciclagem organizacional e tecnológica diante da ameaça japonesa dos anos 1980, como também pela alta desenfreada do valor de suas ações, o que facilitou enormemente o exercício da liderança nos processos de fusão em âmbito mundial.

Por último, mas não menos importante, cabe ressaltar que a dramática intensificação do trânsito internacional de capitais - sejam as aplicações produtivas ou estritamente financeiras - cria a impressão (quase um dogma no início dos anos 1990) de que a atração de capitais é a função primordial dos governos nas nações emergentes. Mais que isso, difunde-se a convicção de que esse processo, desde que conduzido de acordo com as "regras do jogo", não traz ameaças para os países tomadores. $\mathrm{O}$ tema voltará mais adiante.

\section{A NOVA EMPRESA E A NOVA COMPETIÇÃO}

É amplamente admitido hoje que as empresas refletem o seu tempo, havendo pouco em comum entre a firma típica manchesteriana, a fordista e a contemporânea. Juntamente com a evolução das empresas, transformam-se, também, as armas típicas da competição (Lazonick, 1994).

Ford, usualmente referido como símbolo do capitalismo norte-americano, pode também ser apontado como representante máximo de um padrão competitivo hoje superado. De fato, a pretensão de afirmar-se através de um produto bom, barato e sempre igual a si mesmo (o modelo $\mathrm{T}$ ) atinge um auge, mas também praticamente morre, com Henry Ford. O futuro adotaria não apenas a diversificação da GM (ou de Sloam), como armas da competição antes praticamente desconhecidas.

Com efeito, a empresa competitivamente atualizada ganha (e protege) o mercado, através de inovações incessantemente renovadas, design, marketing, customização, serviços pós-venda e desenvolvimento de marcas. Numa palavra, a mera produção, uma vez equacionados os seus problemas iniciais, ten- de a perder o gume, na disputa de mercados. Salvo na medida em que novas maneiras de organizá-la - ou novas escalas - possam ser introduzidas.

Como consequência do anterior - e em resposta ao crescente acirramento da competição - a produção de artigos tecnológica e mercadologicamente maduros tende a ser transferida a plantas (filiais) situadas em economias emergentes. Isso não quer dizer (num mundo em que o princípio da "melhoria permanente" tornou-se uma regra) que cessa inteiramente a evolução dos respectivos produtos. Mas significa que a função fabricação tende a agregar menos valor por unidade de trabalho empregado do que as demais funções corporativas, podendo ser, em certa medida, segregada. Além disso, não é preciso sublinhar que a própria transferência de unidades fabris para mercados emergentes acirra ainda mais a competição a que estão submetidos os mercados de produtos maduros. Importantes consequências do que acaba de ser assinalado serão mais adiante apresentadas.

\section{A CONSAGRAÇÃO DO MERCADO LIVRE E SUA CRÍTICA}

\section{O fracasso das alternativas}

Até os anos 1970 o mundo comportava diversos sistemas socioeconômicos.

A economia norte-americana era a que mais se aproximava do livre-mercado; a Alemanha era a referência principal em se tratando de social-democracia (ou economia social de mercado); o Japão, a Coreia e Taiwan ilustravam os casos em que o Estado liderava o desenvolvimento (developmental states) ${ }^{2}$. E havia, claro, o mundo do socialismo real.

Dentre as grandes mudanças que redefiniram a economia mundial nos anos finais do século XX merece um especial destaque o fracasso mais ou menos evidente das alternativas ao livre mercado.

É fundamental lembrar, a esse respeito, que, além de possuir uma economia de ex-
2 Ver:Wade (2003); Hall \& Soskice (2001) 
cepcional dinamismo, a economia japonesa vinha alcançando - até o final dos anos 1980 notáveis vitórias na competição internacional. A rigor, empresas líderes japonesas estavam impondo novos padrões de conduta e conquistando muitos dos mercados que - através de suas estratégias de longo prazo - decidiam disputar. Assim foi, sobretudo, com os eletrônicos de consumo e com os semicondutores. $\mathrm{E}$ a esse respeito cabe frisar alguns pontos.

Primeiramente, os produtos (e setores) a que acabo de me referir não apenas integram o cerne da nova revolução industrial como, através deles - e das empresas que passavam a liderá-los -, iam se difundindo novos padrões de conduta empresarial. Por outro lado, é também nesse tipo de setor que a Europa sofreu algumas das derrotas que praticamente a retiraram da fronteira da nova revolução industrial. De fato, tanto na área dos eletrônicos de consumo, quanto na área da computação, a liderança passou a ser disputada pelas economias norte-americana e japonesa (Chandler, 2001).

Pode-se, em suma, afirmar que a economia japonesa chegou a dividir com os Estados Unidos a liderança no que toca à nova revolução industrial. Além disso, empresas (e produtos) japonesas vinham colhendo surpreendentes vitórias mesmo em indústrias tradicionais como a automobilística, símbolo, desde o início do século, da supremacia industrial norte-americana. Finalmente, coroava o êxito alcançado por empresas nipônicas a propagação, especialmente nos EUA, de novas formas de organizar o trabalho, gerenciar a produção e relacionar-se com os mercados, se não criadas, pelo menos desenvolvidas e aprimoradas no Japão. Elas viriam, de fato, a definir o ambiente competitivo no limiar do século XXI. Na Europa, por contraste, se constatava uma maior lentidão (ou resistência) na difusão dos novos métodos gerenciais - e a isso iam sendo associadas as dificuldades inerentes a instituições tipicamente europeias (Coriat, Dosi \& Pavitt, 2000).

Em suma, além de arrastar consigo outras economias - como já vinha fazendo com as economias do leste asiático--, a economia japonesa parecia dispor de formas de organização a serem transpostas e adaptadas a outros ambientes socioeconômicos. Mas nada poderia simbolizar melhor a reviravolta ocorrida no Japão do que o seu peso relativo como nação exportadora de capitais. No período de auge daquela economia - de 1986 a 1991 - as saídas de capital do Japão superavam em $28 \%$ as exportações norte-americanas de capitais; em 1997, porém, já haviam caído para meros $23 \%$ do fluxo de saída dos EUA.

Vistos contra esse pano de fundo, a bolha de 1987 a 1990-91 e, a partir desse último ano, o mergulho da economia japonesa numa crise que se arrasta, sem perspectiva de solução, até o presente, são mudanças, a um só tempo, imprevistas e fundamentais. Com elas a economia japonesa passava de liderança a problema, enquanto as suas características socioeconômicas passavam a ser encaradas com ceticismo ou rejeição.

Krugman (2000) fez observações muito provocativas a propósito da crise japonesa. Além de graves problemas financeiros que se arrastam indefinidamente, entre outras razões, pela incapacidade de reconhecer os novos e depreciados valores (pós-bolha dos ativos), foram lá tentados à exaustão remédios que se supunha consagrados para o reerguimento da demanda global. Entre eles, destacadamente, a firme redução da taxa de juros, combinada com estímulos fiscais (reiterados e massivos). Os resultados, no entanto, revelaram-se pífios ou mesmo negativos, dando lugar a uma situação de armadilha da liquidez (com juros praticamente nulos), e, por outro lado, há uma imensa dívida pública.

Isso significa o ressurgimento de um tipo de situação em que a demanda global, após retrair-se seriamente, não parece capaz de ser reavivada por políticas de manejo da demanda - problema que se supunha superado. Tão ou mais importante, significa também que grandes distúrbios no mercado de ativos podem gerar situações de notória e duradoura fragilidade - por melhor que estejam as empresas do ponto de vista competitivo. No caso do Japão, a economia permanece à borda de 
um possível colapso deflacionário. Dessa forma, a mais impetuosa e exitosa das economias capitalistas adquiriu uma vulnerabilidade que, mutatis mutandi, evoca a situação enfrentada por certas economias emergentes. $* * *$

A URSS e o sistema por ela comandado não eram apenas o grande adversário, nos planos político e militar, da então chamada aliança atlântica. Representavam, sobretudo, e no mundo como um todo, a referência alternativa - que até os anos 60 muitos supunham capaz de suplantar o capitalismo.

Contra esse pano de fundo, o desmoronamento soviético alimentou a impressão de "fim da história", com a consagração de um dos termos de uma polarização que marcou décadas. Por outro lado, a solução vitoriosa ficou claramente identificada com o livre mercado - e muito particularmente com a economia norte-americana, contraponto, por excelência, do socialismo. Começa assim a grande comemoração do livre mercado, bandeira assumidamente empunhada pelo governo e pela elite norte-americanos. O movimento só faz crescer até a virada do século, não sendo de admirar que o candidato Bush tenha prometido governar os EUA "como uma corporação".

Além disso, e já foi apontado por diversos autores, o colapso da alternativa sistêmica às economias de mercado reduziu fortemente o poder de barganha das nações atrasadas e empenhadas em afirmar-se.

Enterrada a alternativa socialista e desqualificada a liderança japonesa, os Estados Unidos surgiam como potência incontestável e modelo a ser seguido ${ }^{3}$. Quanto à social-democracia parecia lentamente exaurir-se, num mundo caracterizado pelo acirramento da competição e a quase impossibilidade de proteção de camadas sociais.

\section{Globalização como difusão de regras e instituições}

É difícil não exagerar a importância da interpretação - por muitos convertida em firme convicção - de que o declínio e/ou colapso das alternativas significava a vitória do livre comércio. Em última análise, os problemas que levaram à falência do socialismo, à estagnação da economia japonesa, bem como à modéstia do desempenho da Europa social-democrata - e, claro, aos chamados "fracassos do desenvolvimento" (Hirschman, 1995) -, passam a ser entendidos como consequências de desvios e arbitrariedades frente à liberdade do mercado. A essa ideia seriam ainda associadas duas outras.

Primeiramente, o livre comércio voltaria a ser concebido como uma espécie de estado "natural" - num movimento que recupera a corrente central do pensamento econômico, e pretende condenar todas as formas de intervenção política. A importância decisiva desse ponto é que desaparece com ele a noção de diferentes sistemas socioeconômicos e, no limite, a própria ideia de instituições relevantes e singulares.

O segundo ponto, igualmente decisivo, é a adoção de forma mais ou menos assumida da noção de que a economia norte-americana, constituindo a mais evidente proxy do livre comércio, deve ser tomada como referência - ou, no mínimo, fonte inspiradora. Caberia a ela, como à Inglaterra na segunda metade do século XIX, mostrar aos demais países "a imagem de seu próprio futuro". A esse propósito convém acrescentar que o desempenho crescentemente favorável da economia norte-americana ao longo dos anos 1990 seguramente beneficiou a crença de que não se tratava de um caso nacional. A superioridade norte-americana nada mais seria que o resultado da plena vigência das regras do mercado.

A convicção anterior preparava o terreno para um intenso movimento reformista. A ausência do Estado produtor, a abertura comercial e financeira, a relativa independência do Banco Central, o financiamento das empresas via Bolsa de Valores, a flexibilização do mercado de trabalho, e a importância atribuída à regulação da concorrência, instituições características do moderno capitalismo norte-americano (e até certo ponto do padrão anglo-americano), deveriam ser replicados por toda a parte.
3 A supremacia absoluta trazia consigo problemas que não serão aqui considerados. Deacordocom o perspicaz Giorgi Arbatov, "Faremos a pior coisa possíve para vocês - iremos privá-los do inimigo". 
Tais características passavam a ser entendidas como a própria racionalidade - tudo o mais sendo desvios. Implantá-las passará a ser equiparado a suprimir aberrações ou, na arrogante expressão que correria o mundo, "fazer o dever de casa". Desaparece ou perde sentido, assim, a noção de contexto histórico. Além disso, é impossível não perceber que esse tipo de mudança aplaina o terreno (level the playing field) para a atuação das empresas internacionais. Nesse sentido o movimento era particularmente oportuno. Coincidia com uma fase em que empresas norte-americanas - sobretudo as integrantes da "velha economia" - intensificavam o transplante de fábricas para os chamados BEM (big emerging markets) (Garten, 1996). Sem risco de exagero, pois pode-se afirmar que a globalização enquanto difusão internacional de regras e instituições tendia a levar a hegemonia norte-americana à sua plenitude.

\section{Reformando o resto do mundo: os mercados emergentes}

A abertura mexicana para valer data de 1985 (De la Madrid). O Brasil iniciou o processo, timidamente, no final dos anos 1980 , e acelerou as mudanças em 1990. A Índia começou sua abertura, apenas comercial, em 1990. No caso da Argentina, o regime de políticas adotado em 1991 radicalizou mudanças que, especialmente no caso da abertura comercial, já haviam sido experimentadas no passado recente. Na Coreia a guinada em direção às reformas pró-mercado tem como marco o abandono do planejamento e o esvaziamento das políticas industriais, visando ao ingresso na OCDE. A aceleração das mudanças foi anunciada em 1993, ao ter início o governo Kim Young Sam (Chang, 1998) ${ }^{6}$. Nada se compara, no entanto, em profundidade e radicalismo, à experiência levada a efeito na Rússia e em outras economias ex-socialistas nos primeiros anos da década dos 1990 (Amsdem, Kochanowicz \& Taylor, 1994).

Em todos os casos atribui-se pouca importância às instituições locais. O objetivo não é construir nações, como no pós-guerra, e sim implantar o primado do mercado - daí a denominação mercados emergentes. Mais concretamente, e como já foi sugerido, trata-se de estabelecer ambientes acolhedores, especialmente para o investimento estrangeiro. $\mathrm{E}$, nesse quadro, uma das mais importantes funções das autoridades locais é encontrar a maneira de levar as reformas adiante - e, sobretudo, de torná-las irreversíveis. Essa última função foi, aliás, explicitamente assumida, entre outros, por Leszek Balcerowicz na Polônia, Carlos Salinas no México e Domingo Cavallo na Argentina.

Numa visão mais conceitual essas economias iriam reafirmar ou, eventualmente, descobrir as vantagens comparativas ditadas pelas dotações de recursos. Presumivelmente, o afastamento teria se dado durante a tentativa de industrialização por substituição de importações - mas também através de práticas políticas populistas e, não raro, arroubos nacionalistas. Seria a hora, pois, do retorno às vocações autênticas - na definição das quais poderiam no entanto somar-se critérios contemporaneamente introduzidos, tais como economias de escala, externas e de aprendizado. De qualquer forma, como resultado de novos investimentos, deveriam elevar-se os preços relativos dos fatores abundantes nos mercados recém-abertos, o que, por sua vez, deveria traduzir-se em melhorias na distribuição da renda.

Implicitamente se admitia que empresas procedentes dos países desenvolvidos assumiriam a função de explorar as oportunidades reveladas pelas reformas. Nesse sentido, a elas caberia protagonizar nessas economias.

Na prática, parece hoje claro que as empresas que efetivamente trataram de tirar proveito das novas oportunidades deram substância a um movimento cujas características podem ser sumariadas como segue.

- Os candidatos a integrar a nova onda de extroversão são, fundamentalmente, empresas que já se defrontam com mercados em maior ou menor medida saturados (Garten, 1996).

- As empresas transferem para as economias reformadas, essencialmente, unidades 
produtivas (fábricas). E, dada a prioridade conferida a produtos já bastante trabalhados, será mínimo o esforço local de adaptação de processos ou produtos (Katz, 2000). Em diversos casos se trata de empresas que pretendem disputar espaço com as empresas líderes (usualmente norte-americanas e japonesas), mas, não tendo fôlego financeiro e/ou recursos tecnológicos para enfrentá-las nos mercados desenvolvidos, escolhem fazê-lo nos espaços emergentes.

- Peças, componentes e talvez mesmo matérias-primas seriam adquiridos, preferencialmente, naqueles mercados (e países) que se mostrassem mais aptos a produzi-los. Resultaria disso uma nova divisão internacional do trabalho, mais fragmentada e caracterizada pela expansão das trocas entre empresas originárias do centro (entre si, ou mesmo, individualmente, consigo mesmas). Permitir que as cadeias produtivas fossem dessa forma fatiadas chegou a ser considerado um importante argumento pró-abertura comercial. Por outro lado, não havia, entre os advogados das reformas, qualquer preocupação com o fato de que as demais funções corporativas, que não a fabricação, tendiam a ser retidas pelos países de origem das empresas. Voltaremos ao tema.

Resta acrescentar que, ali onde esse movimento veio efetivamente a tomar corpo, verificou-se uma inédita sobreposição de várias grandes mudanças. Em suma, além da novidade (para os países periféricos) da abertura, estavam também, conjuntamente, sendo introduzidas mudanças associadas às tecnologias da informação, novas formas de organização do trabalho e outras características próprias à competição no mundo globalizado.

\section{UMA NOVA ECONOMIA?}

A combinação das tecnologias da informação (cujas implicações foram anteriormente ressaltadas) com a primazia dos ativos intangíveis, a flexibilidade do mercado de trabalho e instituições do tipo financiamento via mercado de capitais, dá margem ao surgimento da "nova economia".
Em vários planos, o funcionamento da nova economia seria, supostamente, muito diferente do passado. Assim, o pleno emprego não geraria inflação - permitindo que a economia se mantivesse permanentemente num estado de quase-boom. As quedas no mercado de ações, por sua vez, seriam em princípio rapidamente revertidas (correção em V) porque a convicção de que os valores logo voltariam a crescer teria um efeito self-fulfilling. Os desdobramentos do mercado financeiro permitiriam diluir riscos como nunca e, inclusive, alavancar no nascedouro as boas ideias. Através do mercado de capitais de risco e do exuberante negócio dos lançamentos iniciais (IPO), a produtividade elevava-se incessantemente $\mathrm{e}^{7} \mathrm{o}$ valor dos ativos podia indefinidamente se expandir, embalado por resultados a serem alcançados no futuro. E quanto à disparada do valor das ações, não apenas incentivava os gastos (efeito riqueza), como impulsionava o movimento de fusões.

$\mathrm{O}$ modelo anterior permitiu à sabedoria econômica convencional incorporar ingredientes schumpeterianos, como bem o demonstram certos discursos de Allan Greenspan. A liberalização/desregulamentação dos mercados, aliada ao culto do individualismo e da descentralização das decisões, de sua parte, evocam argumentos de procedência hayekiana. A tudo isso se acrescente ainda a preservação de aspectos da chamada síntese neoclássica: o nível de atividades é monitorado e calibrado via política monetária e fiscal - essencialmente a última, desde os anos 1980 e sobretudo na década subsequente.

Já ao tempo em que tudo isso parecia funcionar admiravelmente, alguns suspeitavam de que havia elementos verdadeiros (como a maior internacionalização, e a maior fluidez, bem como a maior pressão competitiva) e ingredientes meramente idealizados (como o desaparecimento dos ciclos) nessa retratação da nova economia. O futuro se encarregaria de mostrar, porém, que nela havia, inclusive, elementos abertamente ideológicos - como a retratação das empresas como entidades transparentes e regidas pela boa governança corporativa.
7 Até os primeiros anos da década, porém, segundo o Nobel Robert Solow, as mu danças trazidas pelas novas tecnologias (e os computadores, em particular) podiam ser vistas em toda parte menos nas estatísti cas de produtividade. 


\section{BIBLIOGRAFIA}

AMSDEN, Alice. Asia's Next Giant: South Korea and Late Industrialization, New York, Oxford University Press, 1989.

AMSDEN, A.; KOCHANOWICZ, J.; TAYLOR, L. The Market Meets its Match. Cambridge, Harvard University Press, 1994.

BEST, Michael. The New Competition. Cambridge, Harvard University Press, 1990.

CASTELS, Manuel. The Rise of the Network Society. New York, Blackwell, 1996.

CHANDLER, Alfred. Inventing the Electronic Century. New York, Free Press, 2001.

CHANG, Ha-Joon. "South Kores, The Misendersttod Crisis", in K. Jomo. Tigers in Trouble. Hong Kong University Press, 1998.

CORIAT, B.; DOSI, G.; PAVITT, K. Dynacom Project. Mimeo., 2000.

FREEMAN, C.; PEREZ, C. "Structural Crises of Adjustment: Business Cycles and Investment Behavior", in Dosi et al. Technical Change and Economic Theory. London, Pinter Publishers. 1988.

GARTEN, Jeffrey. "The Big Emerging Markets", in The Columbia Journal of World Business, 1996.

HALL, Peter; SOSKICE, David. Varieties of Capitalism. Oxford, Oxford University Press, 2001. HIRSCHMAN, Albert. "Industrialization and Its Manifold Discontents: West, East, and South", in A Propensity to Self-Subversion. Cambridge, Harvard University Press, 1995.

KATZ, Jorge. Reformas Estructurales, Productividad y Conducta Tecnológica en América Latina. Santiago, Cepal/Fondo de Cultura Económica, 2000.

KRUGMAN, Paul. The Return of Depression Economics. New York, Norton, 2000.

LAZONICK, William. "Social Organization and Technological Leadership", in William Baumol et al. Convergence on Productivity. Oxford, Oxford University Press, 1994. WADE, Robert. Governing the Economy. New Jersey, Princeton University Press, 2003. 